\title{
A randomized controlled phase llb wound healing trial of cutaneous leishmaniasis ulcers with $0.045 \%$ pharmaceutical chlorite (DAC N-055) with and without bipolar high frequency electro-cauterization versus intralesional antimony in Afghanistan
}

Hans-Christian Stahl ${ }^{1,5}$, Faridullah Ahmadi ${ }^{2}$, Ulrike Schleicher ${ }^{3}$, Rainer Sauerborn ${ }^{1}$, Justo Lorenzo Bermejo ${ }^{4}$, Mohammed Latif Amirih², Ibrahim Sakhayee ${ }^{2}$, Christian Bogdan ${ }^{3}$ and Kurt-Wilhelm Stah $\left.\right|^{5^{*}}$

\begin{abstract}
Background: A previously published proof of principle phase lla trial with 113 patients from Kabul showed that bipolar high-frequency (HF) electro-cauterization (EC) of cutaneous leishmaniasis (CL) ulcers and subsequent moist wound treatment (MWT) closed 85\% of all Leishmania (L.) tropica lesions within 60 days.

Methods: A three-armed phase IIb, randomized and controlled clinical trial was performed in Mazar-e-Sharif. L. tropica- or L. major-infected CL patients received intradermal sodium stibogluconate (SSG) (Group I); HF-EC followed by MWT with 0.045\% DAC N-055 (Group II); or MWT with 0.045\% DAC N-055 in basic crème alone (Group III). The primary outcome was complete epithelialisation before day 75 after treatment start.

Results: 87 patients enrolled in the trial were randomized into group I $(n=24)$, II $(n=32)$ and III $(n=31)$. The per-protocol analysis of 69 (79\%) patients revealed complete epithelialisation before day 75 in 15 (of 23; 65\%) patients of Group I, in 23 (of 23; 100\%) patients of Group II, and in 20 (of 23; 87\%) patients of Group III ( $p=0.004$, Fisher's Exact Test). In the per-protocol analysis, wound closure times were significantly different between all regimens in a pair-wise comparison ( $p=0.000039$, Log-Rank (Mantel-Cox) test). In the intention-to-treat analysis wound survival times in Group II were significantly different from those in Group I ( $p=0.000040$, Log-Rank (Mantel-Cox) test). Re-ulcerations occurred in four (17\%), three (13\%) and seven (30\%) patients of Group I, II or III, respectively ( $p=0.312$, Pearson Chi-Square Test).

Conclusions: Treatment of CL ulcers with bipolar HF-EC followed by MWT with $0.045 \%$ DAC N-055 or with DAC $\mathrm{N}-055$ alone showed shorter wound closure times than with the standard SSG therapy. The results merit further exploration in larger trials in the light of our current knowledge of in vitro and in vivo activities of chlorite. Clinicaltrials.gov ID: NCT00996463. Registered: $15^{\text {th }}$ October 2009.
\end{abstract}

Keywords: Cutaneous leishmaniasis, Wound healing, DAC N-055, Sodium stibogluconate, High-frequency bipolar electrocauterization

\footnotetext{
* Correspondence: stahlkw@orphandrug.org

${ }^{5}$ Waisenmedizin e.V. - PACEM, Freiburg, Germany

Full list of author information is available at the end of the article
} 


\section{Background}

In developed countries chronic wounds are an advanced age disease. In Afghanistan, cutaneous leishmaniasis (CL) ulcers resulting from parasite infections disfigure non-covered parts of the body especially at younger age. Advanced age wounds elicit industrial R\&D efforts, whereas particularly in the Near, Middle and Far East CL wounds constitute a neglected field of clinical research, although their incidence of approximately $0.5 \%$ to $1 \%$ is of the same magnitude $[1,2]$.

In 1986, a randomized controlled trial (RCT) has shown that moist dressing with a sodium chlorite $\left(\mathrm{NaClO}_{2}\right)$ based drug is beneficial for rapid wound cleansing and granulation [3]. If not further concentrated under vacuum (which is commonly practiced with industrial $\mathrm{NaClO}_{2}$ ), pharmaceutical chlorite contains a chlorine peroxide contaminant, formerly called tetradecachlorooxygen (TCDO), a chemical name refuted by the German Health Authorities [4]. The chlorine peroxide seems to be important for systemic regenerative effects in stem cell compartments of rats $[5,6]$. Recent advances in bacterial heme protein biochemistry $[7,8]$ have reformed our understanding of chlorite biochemistry [9] showing that in vivo reactions of chlorite with heme analogues can either produce hypochlorite, which in turn can react with $\mathrm{H}_{2} \mathrm{O}_{2}$ to form singlet oxygen ${ }^{1} \mathrm{O}_{2}$, or which can dismutate to $\mathrm{Cl}^{-}$and ${ }^{1} \mathrm{O}_{2}$. In animal experiments with non-thermal (NTP) [10] or cold atmospheric plasma (CAP) [11] lower $\mu \mathrm{M}$ levels ${ }^{1} \mathrm{O}_{2}$ have shown to induce wound healing.

Simple physical wound debridement practised with bi-polar high frequency electrosurgical cauterisation (HF-EC) as a first step seemed to be of crucial importance [12] to achieve faster wound healing than obtained with sodium stibogluconate (SSG) [13]. As recently advocated [14], special attention should be given to the wound disease character of Old World Cutaneous Leishmaniasis (OWCL) lesions with frequent bacterial and fungal contaminations [15] which are typical for chronic wounds [16].

Within the present randomized controlled three-armed clinical trial we investigated the benefit of applying local wound treatment to OWCL ulcers. The overall aim of this RCT phase IIb trial in Mazar-e-Sharif, Afghanistan, was (a) to confirm previous results [12] using bipolar HFEC combined with subsequent moist wound treatment (MWT) with $0.045 \%$ of the pharmaceutical sodium chlorite solution (DAC N-055); and to directly compare the results (b) with topical anti-parasitic SSG and (c) with $0.045 \% \mathrm{DAC} \mathrm{N}-055 \mathrm{MWT}$ alone, known to promote tissue regeneration $[3,5,6]$. The trial was further encouraged by the previous successful treatment of four patients with facial lupoid leishmaniasis, in whom the topical application of $0.045 \%$ DAC N-055 led to a rejuvenation of the faces $[17,18]$.

\section{Methods}

Trial design

The study was designed as a mono-centric, three armed, open label, randomized (1:1:1), controlled, phase IIb trial with tissue biopsy [19] without any amendments to the protocol after trial start.

\section{Ethics}

Ethical clearance was obtained from the Ethics Committees of the Medical Faculties of Heidelberg and Erlangen in Germany and the International Review Board at the Ministry of Public Health in Kabul, Afghanistan (Clinicaltrials.gov ID: NCT00996463. Registered: $15^{\text {th }}$ October 2009). As nearly all patients could neither read nor write or count, an oral informed consent before patient screening was obtained by the medical doctor after thorough and comprehensible explanation of the aims and the protocol of the clinical trial.

\section{Participants}

Patients presenting CL lesions with Leishmania-positive Giemsa smears without prior CL treatment were included. Exclusion criteria were: age $<12$ years, more than one skin lesion (to exclude intra-individual variations in this phase IIb analysis), lesion age $>3$ months, lesions located on eye lids, lips or nose, drug addiction, coinfection with Mycobacterium tuberculosis or HIV, and diabetes. All patients who had agreed to participate in this trial had respected our call regarding patients' age, lesion age and lesion location. No patients were lost during the screening process due to drug addiction, tuberculosis, HIV infection, or diabetes. Patients not available for follow-up were also ineligible. Medical services and drugs were free of charge and patients received no remuneration.

\section{Location}

The trial was carried out at the Leishmania and Malaria Centre (LMC) of the Provincial Balkh Civil Hospital Mazar-e-Sharif treating 4,000 new CL cases every year [20]. Before trial start the centre was renovated under the supervision of the NGO Waisenmedizin e.V. and equipped with a solar power system guarantying electrical power supply for $24 \mathrm{~h}$ per day.

\section{Data capture system}

Cameras, computers, and the internet-based on- and offline electronic case report system Leishmedoc (Waisenmedizin PACEM e.V. Freiburg, Germany) in combination with Skype $^{\text {mit }}$ (Microsoft Corporation, Redmond, USA) communication enabled real-time trial monitoring from Germany. 


\section{Protocol of visits}

Patients were registered after informed consent (see Ethics) with demographic details, cell phone numbers and a patient's identification number on a patient card. After physical examination, the location and initial state of the lesion were documented and referenced by the patient's identification number and a scale. Six visits were scheduled in the first week, two visits per week from weeks 2 to 4 , and one visit per week thereafter until complete wound closure. Follow-up visits were required once a month until day 180 after treatment start.

\section{Drugs for interventional therapy}

Sodium stibogluconate $(3 \mathrm{~g} / 30 \mathrm{ml})$ was imported from India (Albert David Ltd., India). 4.5\% (500 mM) alkaline sodium chlorite solution for pharmaceutical use (DAC N-055; Kyrochem GmbH, Wedemark, Germany) was diluted in the constituent formulas of the poly-acrylate jelly and basic crème (Additional files 1 and 2). The German DAC N-055 contains peroxides [21] $\left(\mathrm{Na}_{2} \mathrm{Cl}_{2} \mathrm{O}_{6}\right.$ and $\mathrm{NaCClO}_{6}$ ) at an app. 1:10 molar ratio, if produced from chlorine dioxide in a way to minimize the chlorate content. DAC N-055, formerly known as TCDO, promotes tissue regeneration, as does hydrogen peroxide at concentrations $<10^{-5} \mathrm{M}[22,23]$. In contrast to hydrogen peroxide, DAC N-055 is catalase (EC 1.11.1.6) resistant [24]. Vials of sterile distilled water and $1 \%$ lidocaïne were purchased from local pharmacies in Mazar-e-Sharif. Jellies were freshly prepared every day by the dermatologist (IS) of the Balkh Province Civil Hospital of Mazar-e-Sharif, who had been trained in the Unguator ${ }^{\circ}$ Technology $\left(\mathrm{GAKO}^{\circ}\right.$ International $\mathrm{GmbH}$, Munich, Germany) at the Pharmaceutical Institute of the University Freiburg, Germany. EuRho DAC 2003 cream (Euro OTC Pharma $\mathrm{GmbH}$, Bönen, Germany) is a magistral preparation available in German pharmacies (Additional file 2).

\section{Other drugs}

In case of clinically diagnosed wound infections, topical wound disinfection was allowed for 5 consecutive days with saline containing $970 \mathrm{ppm}$ chlorine dioxide (freshly prepared by acidification of $0.27 \%$ DAC N-055 in physiological saline to $\mathrm{pH}$ 5). In case of failure, a systemic therapy with antibiotics or with anti-mycotics of little anti-parasitic effect was recommended. Prontosan ${ }^{\circ}$ (B. Braun Medical AG, Sempach, Switzerland) with the detergent undecylenamidopropyl betaïne (CAS 133798-126) at a concentration of $0.1 \%$ was used for gently sloughing off crusts after SSG injections to detect complete epithelialisation (Figure 1).

\section{Medical devices for interventional therapy}

The electrosurgical Minicutter ${ }^{\mathrm{Tm}}$ with a specially designed bipolar angled forceps with a $1 \mathrm{~mm}$ distance holder and a maximum bipolar current mode of $70 \mathrm{~mA}$ (HMC 80 HF Chirurgie, KLS Martin, Umkirch, Germany) was imported from Germany.

\section{Randomization}

The LMC principal dermatologist investigator (IS) determined the patients' eligibility. Each patient was randomly assigned to one of the three regimens by the random allocation generator in the computer-based Leishmedoc system.

\section{Treatment protocols}

The patients' OWCL lesion was treated (1) by intradermal injections of $0.6 \mathrm{ml} \mathrm{SSG}$ according to a protocol used by Zeglin (2009) [25] (Group I), or (2) by aseptic MWT with $0.045 \%$ DAC N-055 following a single initial superficial wound debridement with HF-EC which was performed under local anaesthesia after wound cleansing and disinfection with gauzes soaked in physiological saline solution containing $320 \mathrm{ppm}$ chlorine dioxide $(\mathrm{pH} 5.5$ acidified $0.09 \%$ DAC N-055) for 15 minutes (Group II), or (3) by MWT with $0.045 \%$ DAC N-055 alone (Group III).

The topical treatment schedule was identical in all three regimens: daily treatments (with the exception of Fridays) during the first week, followed by topical treatments at the LMC twice a week until the end of week 4 and thereafter once a week until wound closure. In
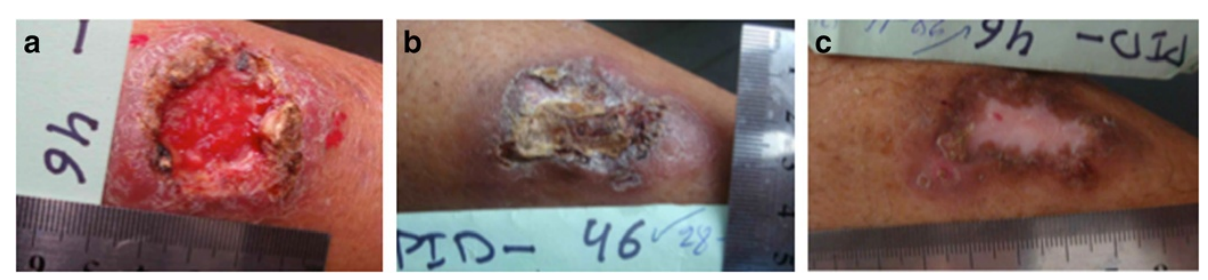

Figure 1 Photo-documentation of wound epithelialization of crusted lesions after removal of the crusts. (Panel a) Lesion status prior to the start of the intradermal SSG treatment start at day 0; (Panel b) Lesion status after 12 intradermal SSG injections on day 51; (Panel c) Lesion status after gentle sloughing off with Prontosan ${ }^{\oplus}$ detergent on day 90. Crusts, that were close to slough off, were removed after 30 min incubation with aseptic $0.1 \%$ Prontosan ${ }^{\otimes}$ containing the detergent undecylenamidopropyl betaine. Afterwards, the wound was photo-documented including the patient's identification number and a linear scale to analyse the wound size. 
Group I, the SSG treatment was discontinued after week 4. In Groups II and III, patients dressed their lesion themselves after week 4 with the topical $\mathrm{NaClO}_{2}$-basiccrème between their visits at the LMC until lesion closure.

The HF-EC debridement started with a superficial coagulation of the epidermis using the strongest relative current of the Minicutter ${ }^{\text {Tm }}$ (position 10) for approximately two seconds necessary to boil off the excess physiological saline on the lesion. After the coagulated epidermis was mechanically removed with moist gauze, the parasite infected dermal layer became visible as a reddish granulomatous area and was specifically targeted by a second coagulation until the area turned into a slightly brownish colour. This procedure was performed only once. The wounds of Groups II and III were dressed with a EuRho ${ }^{\circ}$ DAC 2003 cream preparation (Additional file 2) until lesion closure, with the exception of Group II, in which for 6 days after HF-EC debridement of the CL lesions the wounds were daily dressed with freshly prepared poly-acrylate jelly containing $0.045 \%$ DAC N-055 (Additional file 1).

During week 1, patients of Groups II and III and their relatives were trained to dress wounds, receiving $10 \mathrm{~g}$ EuRho ${ }^{\circ}$ DAC 2003 cream containing 0.045\% DAC N055, in a sterile syringe, which allowed self-treatment for 3 weeks.

\section{Parasitological analyses and Leishmania species determination}

At the LMC, Leishmania parasites within the lesion were confirmed with the slit-skin method described by Al Hucheimi [26]. In addition, skin biopsies were taken from the margins of the lesions and placed into modified Schneider's Drosophila insect medium, transported with the German Army to the Microbiology Institute in Erlangen, Germany, where mini-exon polymerase chain reaction (PCR) and multiple restriction fragment length polymorphism analyses for parasite species determination and limiting dilution analyses for determination of the parasite loads per gram biopsy tissue were carried out as previously described [12].

\section{Outcome}

The primary outcome of the study was the ratio of closed versus open wounds at day 75 (D75) in the PP analysis for each regimen.

\section{Sample size}

The specific hypotheses were (i) that the proportion of primary closed lesions before D75 is significantly higher in patients treated with HF-EC with subsequent MWT using $0.045 \%$ DAC N-055 (Group II) than in patients who received topical intradermal SSG (Group I); and (ii) that MWT with $0.045 \%$ DAC N-055 alone, which is known to exert tissue regenerative activity in vivo $[3,18]$, also promotes the closure of chronic Leishmania lesions (Group III).

The sample size calculation was based on the perprotocol (PP) analysis, defined as all patients evaluable with respect to the primary endpoint. Based on the Reithinger [13] trial and our previous findings in Kabul [12] we defined D75 as endpoint to evaluate a clinically relevant difference of $40 \%$ between the percentage of wound closures in Group I (50\% at D75) and Group II (90\% at D75), respectively. We assumed that SSG chemotherapy does not directly accelerate the wound healing process. In Group III a percentage of $75 \%$ at D75 was estimated, since MWT promotes wound healing. A power calculation based on Group I and II showed that 42 patients were needed in each arm to reject the null hypothesis of equal cure rates with a $90 \%$ probability using the Fisher's exact test (Type I error probability 1\%). An interim analysis was planned when $50 \%$ of the patients $(42 / 2=21)$ had efficacy assessments. Bonferroni adjustment was used to calculate $\mathrm{p}_{1}=2 \mathrm{p}_{\min }$, where $\mathrm{p}_{\text {min }}$ was the smallest of $\mathrm{p}_{\text {Group I vs Group II versus }}$ PGroup I vs Group III [27]. Based on the pre-specified stopping boundaries $\alpha_{1}=0.01, \beta_{1}=0.15$ and $\alpha_{2}=0.1871$ and decision rules (Additional file 3 ), the trial could be stopped at stage I for efficacy.

\section{Statistical analysis}

The present trial is a phase IIb efficacy assessment trial. The intention-to-treat analysis (ITT) is solely added as additional information. Patients that could not be evaluated were patients that were lost immediately after registration before treatment started. Within the group of evaluable patients we distinguished between patients whose lesion could be evaluated with respect to D75 and those that were lost to follow-up before D75 with no wound closure. The former were included in the per-protocol-analysis (PP) and the latter were additionally included in the ITT. Screened patients lost immediately after registration, were not included in our definition of the ITT analysis.

Baseline characteristics were analysed using the Pearson Chi-Square Test or the Kruskal-Wallis Test. Primary outcome was evaluated using the Fisher's Exact Test. Wound closure times were calculated with Kaplan-Meier survival analysis. Hazard ratios and potential covariates were analysed with Cox-Regression. Re-ulceration rates were compared using the Pearson Chi-Square Test. Statistical analyses were performed with $\mathrm{IBM}^{\oplus}$ SPSS $^{\oplus}$ Statistics version 21 (IBM Deutschland $\mathrm{GmbH}$, Ehningen, Germany), except the statistics on the Leishmania load per gram biopsy tissue that were calculated with GraphPad Prism version 4.0 (Graphpad Software Inc., La Jolla, CA, USA). 


\section{Results}

\section{Enrolled patients}

In total, 87 patients were enrolled, with 24 (27.5\%), 32 (36.8\%), and 31 (35.6\%) in Groups I, II, and III, respectively (Figure 2). 81 out of 87 patients (93.1\%) were suitable for the ITT and $69(79.3 \%)$ for the PP analysis (Additional file 4).

\section{Recruitment}

Patients were enrolled from November 2009 to August 2010. The efficacy value of $\mathrm{p}_{1}$ was found smaller than the stopping boundary of $\alpha_{1}=0.01$ pre-defined in the protocol. Therefore the study was stopped (Additional file 3$)$.

\section{Baseline data}

Sixty-nine patients (37 [54\%] females, 32 [46\%] males) with a mean age of 29 years (CI 25-33) followed the protocol. The analysed baseline data were comparable in all three regimens in the PP (Table 1) as well as ITT analysis (Table 2). In 44 out of 69 patients analysed, 28 (64\%) lesions were infected with L. tropica and 16 (36\%) with L. major. L. major infections dominated from September to March, L. tropica from March to August.

\section{Primary outcome}

15 out of 23 (65\%), 23 out of 23 (100\%), and 20 out of $23(87 \%)$ patients attained complete epithelialisation until D75 in Groups I, II and III, respectively (Group I

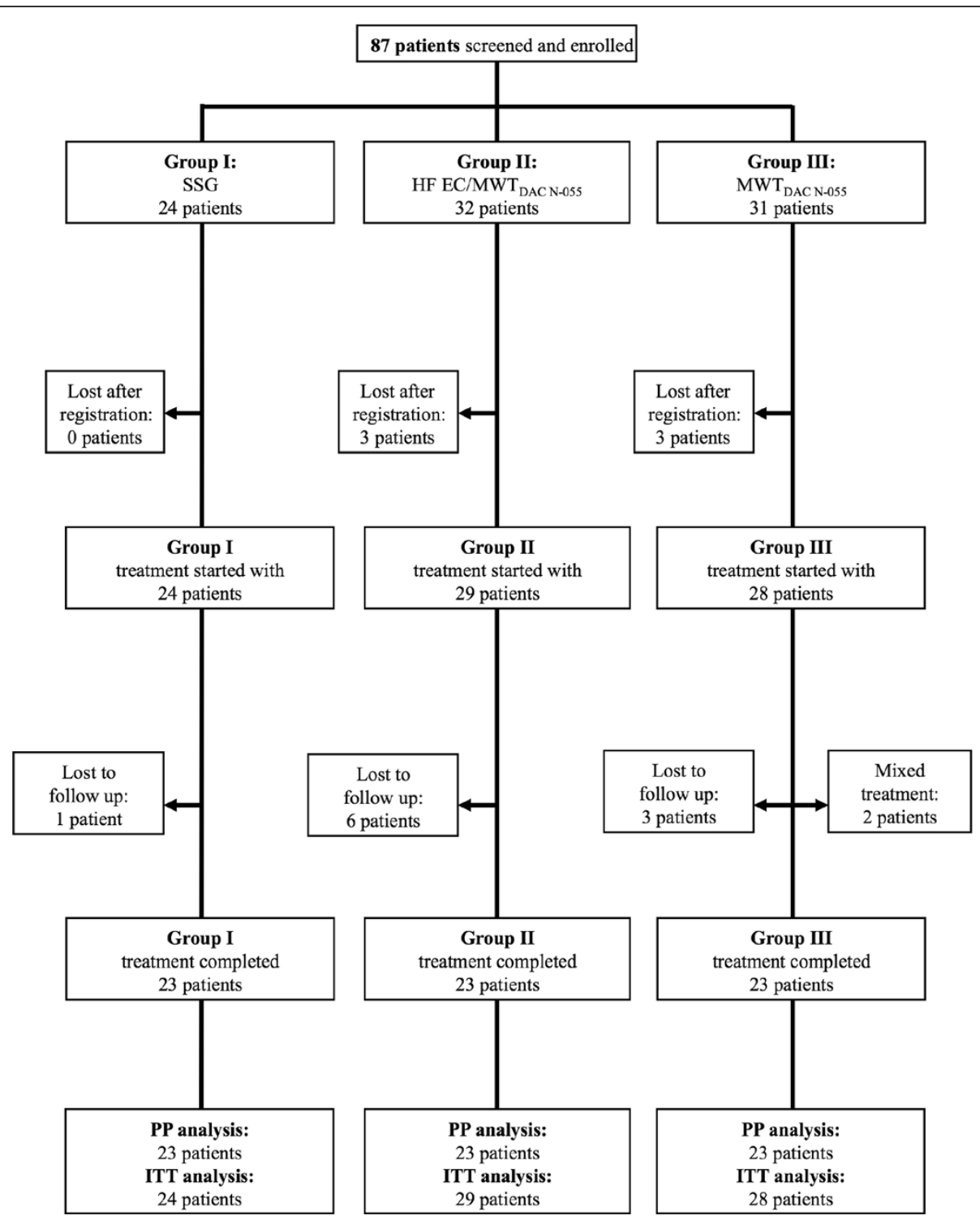

Figure 2 Flow chart summarizing the enrolment, randomization, and follow-up of study patients. 
Table 1 Baseline characteristics of the PP patients enrolled in the three treatment groups of the trial

\begin{tabular}{|c|c|c|c|c|c|c|}
\hline & \multicolumn{5}{|c|}{ Per protocol (PP) evaluation } & \multirow[t]{2}{*}{ Test } \\
\hline & Group I & Group II & Group III & Total & p-value & \\
\hline Male & 13 & 8 & 11 & 32 & & Pearson Chi-Square \\
\hline Female & 10 & 15 & 12 & 37 & $0.372^{*}$ & Test (Exact-Sig.) \\
\hline Age $(95 \% \mathrm{Cl})$ & $26(19-34)$ & $28(22-33)$ & $33(25-40)$ & $29(25-33)$ & $0.308^{*}$ & Kruskal-Wallis Test \\
\hline Lesion age $(95 \% \mathrm{Cl})$ & $9(7-11)$ & $8(7-10)$ & $7(6-9)$ & $8(7-9)$ & $0.437^{*}$ & Kruskal-Wallis Test \\
\hline Lesion size $(95 \% \mathrm{Cl})$ & $3.7(2.3-5.0)$ & $2.5(1.7-3.3)$ & $3.0(2.0-4.1)$ & $3.1(2.5-3.7)$ & $0.421^{*}$ & Kruskal-Wallis Test \\
\hline \multicolumn{7}{|l|}{ Parasite species } \\
\hline L. major & 4 & 5 & 7 & 16 & & \\
\hline L. tropica & 5 & 13 & 10 & 28 & & Pearson Chi-Square \\
\hline Not determined & 14 & 5 & 6 & 25 & $0.664^{*}$ & Test (Exact-Sig.) \\
\hline \multicolumn{7}{|l|}{ Lesion location } \\
\hline Head & 5 & 3 & 2 & 10 & & \\
\hline Trunc & 0 & 0 & 1 & 1 & & \\
\hline Upper extr. & 12 & 16 & 14 & 42 & & Pearson Chi-Square \\
\hline Lower extr. & 6 & 4 & 6 & 16 & $0.666^{*}$ & Test (Exact-Sig.) \\
\hline \multicolumn{7}{|l|}{$\begin{array}{l}\text { Parasite load according to } \\
\text { Giemsa staining }\end{array}$} \\
\hline Low $(+)$ & 12 & 11 & 8 & 31 & & \\
\hline Moderate $(++)$ & 8 & 12 & 14 & 34 & & \\
\hline High $(+++)$ & 1 & 0 & 1 & 2 & & Pearson Chi-Square \\
\hline Not determined & 2 & 0 & 0 & 2 & $0.541^{*}$ & Test (Exact-Sig.) \\
\hline \multicolumn{7}{|l|}{ Biopsy prior to treatment } \\
\hline Evaluable & 16 & 18 & 17 & 51 & & Pearson Chi-Square \\
\hline Not evaluable & 7 & 5 & 6 & 18 & $0.940^{*}$ & Test (Exact-Sig.) \\
\hline Parasite load/g tissue (SEM) & $2.944(1.645) \times 10^{6}$ & $3.081(1.980) \times 10^{6}$ & $2.773(1.785) \times 10^{6}$ & $2.935(1.032) \times 10^{6}$ & $0.636^{*}$ & Kruskal-Wallis Test \\
\hline
\end{tabular}

Statistical tests were used as indicated ( $<0.05$ indicates a significant proportion, ${ }^{*} \mathrm{p}$-values refer to observations with complete information).

versus II: $\mathrm{p}=0.004[\mathrm{PP}]$; Table 3 ). For the intention to treat results see Table 4 .

\section{Secondary outcome}

The frequent attendance of the study participants allowed plotting wound survival curves (Figures 3 and 4). In a Kaplan-Meier analysis (days until primary wound closure), the survival curves of the three investigated treatments differed significantly in an overall comparison $(\mathrm{p}=0.000039$ [PP]; $\mathrm{p}=0.000616$ [ITT], Log-Rank [Mantel-Cox] test). In the ITT analyses, mean and median lesion wound survival times in Group II (35 [CI 30-40]/34 days [CI 29-39]) were significantly different from those in Group I (69 days [CI 50-90]/63 days [CI 50-75]) (Tables 5 and 6); in contrast, the pair-wise comparison of the Group III versus Group I survival times did not reveal significant differences $(\mathrm{p}=$ 0.508, Log-Rank [Mantel-Cox] test) (Tables 5 and 6). In the PP analysis, pair-wise comparison for all three groups showed significant differences in wound survival time $(\mathrm{p}=$ 0.023 [Group II vs. III]; $\mathrm{p}=0.047$ [Group III vs. I], LogRank [Mantel-Cox] test) (Tables 6 and 7). Hazard ratios of
Group II versus Group I equaled to 4.415 (CI 2.219-8.783) in the PP ( $\mathrm{p}=0.000023)$ and 3.270 (CI 1.687-6.341) in the ITT analysis ( $p=0.000453)$. The lesion closed three to four times faster in Group II than in Group I.

\section{Covariates analysis}

In the Cox-regression analysis, gender, age of the patient age, and age of the lesion were no significant covariates for primary closure. Lesion size at baseline was a significant $(\mathrm{p}=0.016)$ covariate with a hazard ratio of 0.883 (CI 0.798-0.977) in the PP, but not in the ITT analysis $(\mathrm{p}=0.312)$ with a hazard ratio of $0.954(\mathrm{CI} 0.872-1.045)$.

\section{Non-desired effects (NDEs)}

In the PP analysis, re-ulceration rates were similar in Group I (four patients) and in Group II (three patients), but were more frequent in Group III (seven patients) $(\mathrm{p}=0.312$, Pearson Chi-Square test). No final closure was documented for two patients (D131 and D269), one patient (D186), and five patients (D90, D142, D143, D143, D176) in Groups I, II, and III respectively. The 
Table 2 Baseline characteristics of the ITT patients enrolled in the three treatment groups of the trial

\begin{tabular}{|c|c|c|c|c|c|c|}
\hline & \multicolumn{5}{|c|}{ Intention to treat (ITT) evaluation } & \multirow[t]{2}{*}{ Test } \\
\hline & Group I & Group II & Group III & Total & p-value & \\
\hline Male & 14 & 12 & 15 & 41 & & Pearson Chi-Square \\
\hline Female & 10 & 17 & 13 & 40 & $0.446^{*}$ & Test (Exact-Sig.) \\
\hline Age $(95 \% \mathrm{Cl})$ & $26(19-33)$ & $28(23-33)$ & $32(25-38)$ & $29(25-32)$ & $0.252^{*}$ & Kruskal-Wallis Test \\
\hline Lesion age $(95 \% \mathrm{Cl})$ & $9(7-10)$ & $9(8-11)$ & $7(6-8)$ & $8(7-9)$ & $0.187^{*}$ & Kruskal-Wallis Test \\
\hline Lesion size $(95 \% \mathrm{Cl})$ & $3.6(2.3-4.9)$ & $2.3(1.7-3.0)$ & $2.7(1.8-3.6)$ & $2.8(2.3-3.4)$ & $0.204^{*}$ & Kruskal-Wallis Test \\
\hline \multicolumn{7}{|l|}{ Parasite species } \\
\hline L. major & 5 & 7 & 9 & 21 & & \\
\hline L. tropica & 5 & 14 & 11 & 30 & & Pearson Chi-Square \\
\hline Not determined & 14 & 8 & 8 & 30 & $0.614^{*}$ & Test (Exact-Sig.) \\
\hline \multicolumn{7}{|l|}{ Lesion location } \\
\hline Head & 5 & 4 & 4 & 13 & & \\
\hline Trunc & 0 & 0 & 1 & 1 & & \\
\hline Upper extr. & 12 & 19 & 16 & 47 & & Pearson Chi-Square \\
\hline Lower extr. & 7 & 5 & 7 & 19 & $0.799^{*}$ & Test (Exact-Sig.) \\
\hline \multicolumn{7}{|c|}{ Parasite load according to Giemsa staining } \\
\hline Low $(+)$ & 13 & 16 & 11 & 40 & & \\
\hline Moderate $(++)$ & 8 & 13 & 16 & 37 & & \\
\hline High $(+++)$ & 1 & 0 & 1 & 2 & & Pearson Chi-Square \\
\hline Not determined & 2 & 0 & 0 & 2 & $0.534^{*}$ & Test (Exact-Sig.) \\
\hline \multicolumn{7}{|l|}{ Biopsy prior to treatment } \\
\hline Evaluable & 17 & 23 & 22 & 62 & & Pearson Chi-Square \\
\hline Not evaluable & 7 & 6 & 6 & 19 & $0.800^{*}$ & Test (Exact-Sig.) \\
\hline Parasite load/g tissue (SEM) & $2.773(1.554) \times 10^{6}$ & $3.430(1.736) \times 10^{6}$ & $2.368(1.526) \times 10^{6}$ & $2.889(0.932) \times 10^{6}$ & $0.691^{*}$ & Kruskal-Wallis Test \\
\hline
\end{tabular}

Statistical tests were used as indicated ( $p<0.05$ indicates a significant proportion, ${ }^{*} p$-values refer to observations with complete information).

number of patients in the three arms of this trial was to small to make a meaningful comparison as to which treatment mode yields the best cosmetic scar outcome. However, in Group II, the flat scars showed the typical livid borders with hypo-pigmented central zones, taking weeks to months to fade away as also observed in our previous phase IIa trial in Kabul [12]. In Group II, two scar keloïds (8.6\%, $4 \mathrm{~mm}$ in diameter) formed at D172 and D239.

\section{Discussion}

This phase IIb study was conducted according to the state of the art in the analysis of chronic wound

Table 3 Per protocol analysis of the primary endpoint

\begin{tabular}{llllll}
\hline & \multicolumn{4}{l}{ Per protocol (PP) evaluation } \\
\cline { 2 - 6 } & Group I & Group II & Group III & Total & p-value \\
\hline < D75 & 15 & 23 & 20 & 58 & \\
$\geq$ D75 & 8 & 0 & 3 & 11 & $0.004^{*}$ \\
Unknown & NA & NA & NA & NA & \\
Total & 23 & 23 & 23 & 69 & \\
\hline
\end{tabular}

*Pearson Chi-Square Test (Exact-Sign). healing $[28,29]$ and anticipated recommendations for RCTs in CL [30]. Rapid healing in Group II confirmed the robustness of the findings in the Kabul trial [12].

\section{Limitations}

By its nature the present trial could not be conducted as either a double or a single blinded trial due to the physical nature of the applied interventions.

Table 4 Intention to treat analysis of the primary endpoint

\begin{tabular}{llllll}
\hline & \multicolumn{5}{l}{ Intention to treat (ITT) evaluation } \\
\cline { 2 - 6 } & Group I & Group II & Group III & Total & p-value \\
\hline < D75 & 15 & 23 & 20 & 58 & \\
$\geq$ D75 & 8 & 0 & 4 & 12 & \\
Unknown & 1 & 6 & 4 & 11 & $0.009^{*}$ \\
Total & 24 & 29 & 28 & 81 & \\
\hline
\end{tabular}

*Pearson Chi-Square Test (Exact-Sign). 


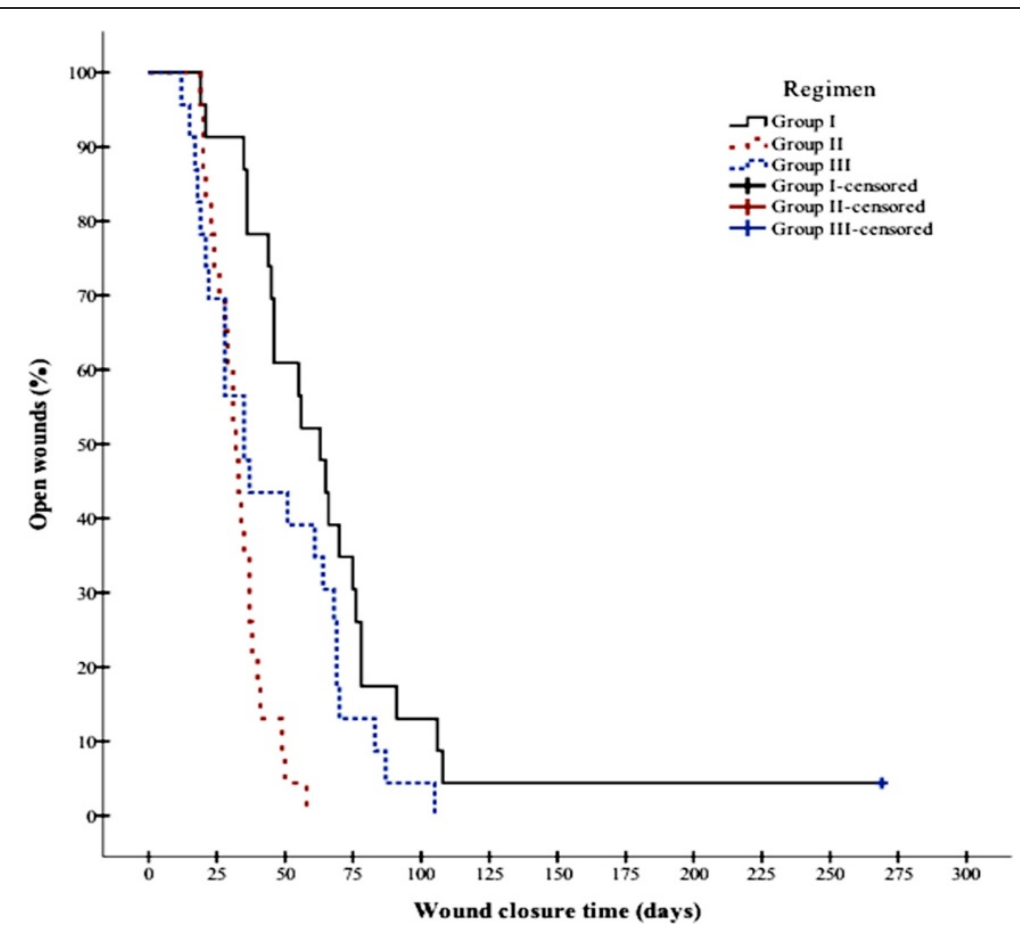

Figure 3 Wound closure time in PP patients of Group I versus Group II versus Group III. Statistically significant difference between Group II versus Group I ( $p=0.000001$, Log-Rank [Mantel-Cox] test). Statistical significant differences were found between all groups (see Table 6).

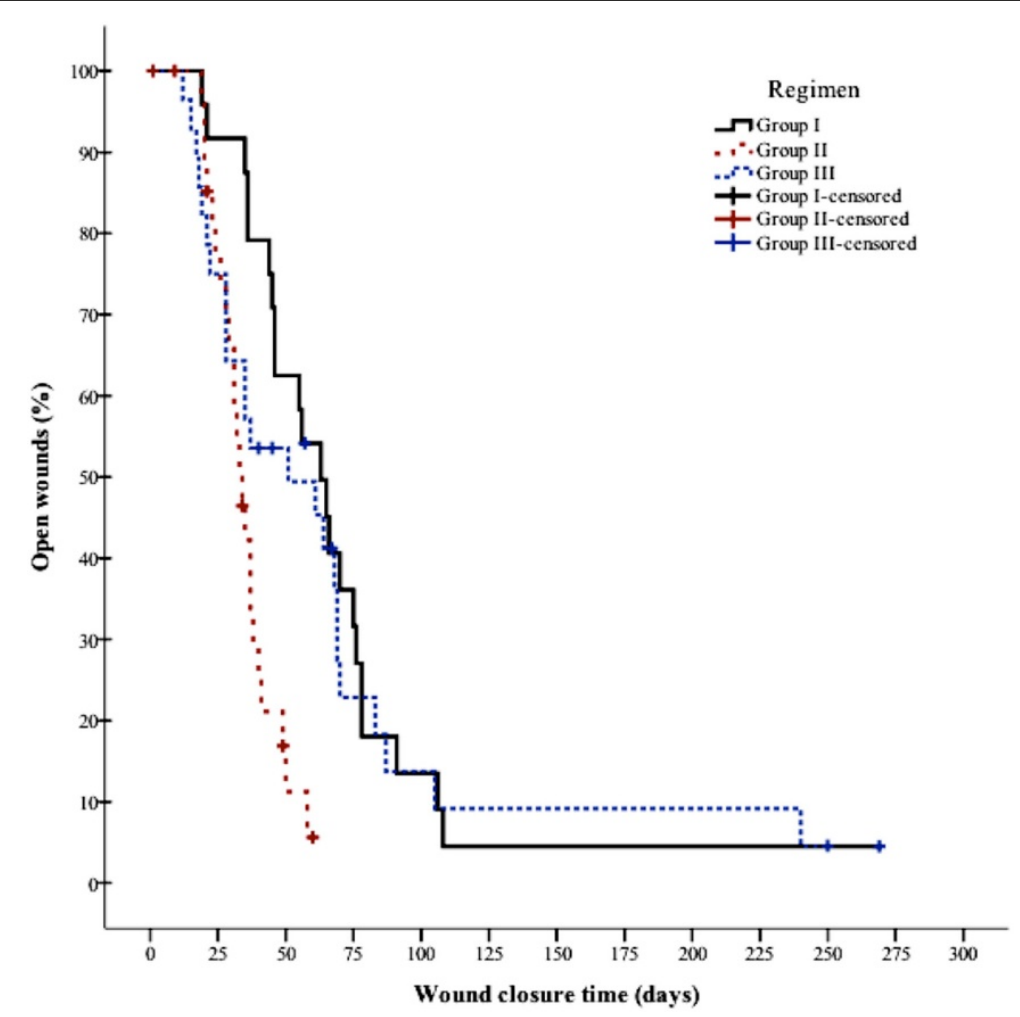

Figure 4 Wound closure time in ITT patients of Group I versus Group II versus Group III. Statistically significant difference between Group II versus Group I ( $p=0.00004$, Log-Rank [Mantel-Cox] test). 
Table 5 Intention to treat analysis of mean and median wound survival time (days)

\begin{tabular}{lllll}
\hline & \multicolumn{4}{l}{ Intention to treat (ITT) evaluation } \\
\cline { 2 - 5 } & Group I & Group II & Group III & Overall \\
\hline Mean (95\% CI) & $69(50-90)$ & $35(30-40)$ & $66(41-91)$ & $58(46-70)$ \\
Median (95\% Cl) & $63(50-75)$ & $34(29-39)$ & $51(17-85)$ & $44(32-56)$ \\
\hline
\end{tabular}

\section{Generalizability}

So far, six physical treatment regimens have been proposed and clinically tested to disinhibit the healing delay of chronic wounds. In CL ulcers, thermotherapy (TT) $[13,31,32]$ sparing host tissue, photodynamic therapy (PDT) [33-35] producing tissue ${ }^{1} \mathrm{O}_{2}$ [36], cryotherapy $\left(\mathrm{N}_{2}\right)$ [37-39], $\mathrm{CO}_{2}$ laser [40-43], and HF-EC [12] all elicited short-term constructive inflammatory reactions with beneficial ROS production in the tissue [44] and destroyed parasites and commensal bacteria together with host cells. Similarly, CAP presumably also acted by forming ROS in non-CL skin lesions $[45,46]$. After initial debridement by HF-EC CL ulcers healed despite of residual, persisting parasites, and MWT treatment with pharmaceutical chlorite showed an additional beneficial healing effect in lesions with high pre-treatment parasite loads [12]. In 2008, González et al. highlighted on page 33 of their Cochrane meta-analysis: "We found no RCTs on the use of wound healing to treat OWCL" [47]. This initiated the introduction of MWT with $0.045 \%$ DAC N055 alone as third regimen in the present $\mathrm{RCT}$, without previous HF-EC treatment.

\section{Interpretation}

Pharmaceutical chlorite did not shorten wound-healing times in the Kabul trial [12], when it was performed after HF-EC wound debridement, which already promoted wound granulation to a maximum extent. However, in spite of the small sample size of the present trial, MWT with $0.09 \%$ DAC N-055 alone showed a significantly shorter wound closure time in the PP analysis than topical anti-parasitic SSG, suggesting that pharmaceutical chlorite has an intrinsic effect on wound healing, even if such wounds result from parasitic infections.

Reactive oxygen species (ROS) seem to be prominently involved in wound healing pathology and physiology. At tissue levels above $10^{-4} \mathrm{M}$, ROS including ${ }^{1} \mathrm{O}_{2}$ are

Table 6 P-values: pairwise comparison of the survival functions

\begin{tabular}{llll}
\hline & Group I & Group II & Group III \\
\hline Group I & & $0.000001 / 0.000040$ & $0.047032 / 0.507623$ \\
Group II & $0.000001 / 0.000040$ & & $0.022813 / 0.013589$ \\
Group III & $0.047032 / 0.507623$ & $0.022813 / 0.013589$ & \\
\hline
\end{tabular}

Log-Rank (Mantel-Cox) test, p-values refer to the per-protocol (left value) and the intention-to-treat analysis (right value).
Table 7 Per protocol analysis of mean and median wound survival time (days)

\begin{tabular}{lllll}
\hline & \multicolumn{4}{l}{ Per protocol (PP) evaluation } \\
\cline { 2 - 5 } & Group I & Group II & Group III & Overall \\
\hline Mean (95\% Cl) & $69(49-89)$ & $33(29-37)$ & $45(34-56)$ & $49(41-57)$ \\
Median (95\% Cl) & $63(47-79)$ & $32(27-37)$ & $35(21-49)$ & $37(31-43)$ \\
\hline
\end{tabular}

cytotoxic and may act as cell aging signals [22,48]; below a tissue concentration of $10^{-5} \mathrm{M}$, ROS promote cell proliferation and tissue repair (granulation, neo-angiogenesis and epithelialisation) [22]. This explains the dose-related effect of NTP on mammalian cells, which produces ROS [11], ranging from inducing apoptosis to increasing cell proliferation [44]. This could also explain, why nonconstructive inflammation with ROS production $>10^{-4} \mathrm{M}$ inhibits wound healing, whilst constructive inflammation with ROS production $<10^{-5} \mathrm{M}$ promotes tissue regeneration and wound closures [49,50], similarly to CAP [51].

Liquid nitrogen, the $\mathrm{CO}_{2}$ laser, bipolar HF-EC, PDT, and pharmaceutical chlorite applied to the wound $[3,5,6]$ or to the skin $[17,18]$, where $\mathrm{NaClO}_{2}$ reacts with heme or bacterial dismutases, are likely to have a common denominator for the of wound healing, which might be ${ }^{1} \mathrm{O}_{2}$ or other ROS.

0.045\% DAC N-055 basic crème contains $5 \mathrm{mM}$ $\mathrm{NaClO}_{2}$ diffusing slowly into the skin and wound tissue. For $\mathrm{NaClO}_{2}$ to act as a protracted source of ${ }^{1} \mathrm{O}_{2}$ in the range of $10^{-5}$ to $10^{-6} \mathrm{M}$ in the wound tissue, it would be sufficient that 1 to $10 \%$ of the applied DAC N-055 inoculum enters a heme-catalyzed dismutase reaction which leads to the formation of hypochlorite and subsequently to ${ }^{1} \mathrm{O}_{2}$. In 1984 , it was apparently wrong to speculate on pharmaceutical chlorite as a direct source of oxygen supply for the respiratory chain [52].

Skin defects are always at risk of microbial colonization and infection, especially in the problematic hygienic hospital environment of poor countries such as Afghanistan. Therefore, rapid wound closure is highly desirable. Moreover, physical treatment techniques have the advantage that they do not induce parasite resistance, which is an increasing concern for CL therapy with pentavalent antimony [53].

In contrast to HF-EC, less intrusive therapies such as the application of $\mathrm{N}_{2}$ or PDT are not administered in "one session only" and require supposedly more resources. Both the $\mathrm{CO}_{2}$ laser and bipolar HF-electrosurgery have been used for single session debridement in patients with as many as 4-5 lesions (Reto Steiner and KW Stahl, German Medical Service Kabul, unpublished results). However, in contrast to the $\mathrm{CO}_{2}$ laser, the HF-EC device is a robust instrument with practically no maintenance costs for decades. The HF-EC device can be run with a car battery in the absence of electrical power supply. In contrast to a 
$\mathrm{CO}_{2}$ laser, bipolar HF-EC treatment is more superficial, allows a loophole-free destruction of the lesion tissue, and the cauterization process is less unrestricted in space than with laser beams, which induce deep and very narrow thermal tissue coagulation [54]. From our experience in Kabul with the German Medical Service (GMS), the $\mathrm{CO}_{2}$ laser seems to be especially helpful to treat multiple small recurrent $\mathrm{CL}$ lesions in the face.

Already in 2005, results from murine experiments have claimed that the wound repair response controls the outcome of cutaneous leishmaniasis [55], but so far, to our knowledge, this has not inspired any clinical research work to test this hypothesis in humans. Of course, direct extrapolation from "mice to men" is problematic and our clinical results do not give any straightforward answer to the question, whether mechanisms found in the mouse model also apply to humans [56-58]. However, it is noteworthy to mention that a high degree of microbial and fungal contaminations and superinfections have been observed in leishmanial wounds [15]. They lead to chronic inflammatory processes which counteract the wound healing and involve peroxidase secretions from macrophages and neutrophils. Interestingly, recent biochemical work has shown that human peroxidases, such as lactoperoxidase and myeloperoxidase, are key targets of $\mu \mathrm{M}$ concentrations of chlorite, which destroys these enzymes by heme catalysis [59].

\section{Non-desired effects}

Every scarring process of full thickness wounds with or without topical CL treatment comprises an inevitable risk of late keloïd formation. Keloïds were registered in six $(5.3 \%)$ patients within the phase IIa trial in Kabul [12] and in two (8.7\%) patients of Group II in the present RCT. Asilian and colleagues found hypertrophic scars in five (6\%) patients treated with $\mathrm{CO}_{2}$ laser [41]. Wound healing in the absence of a strong parasitocidal intervention (Group III) seemed to bear a higher risk of reulcerations than observed in Groups I and II, where parasites were killed by SSG or HF-EC, respectively. As DAC N-055 has a strong wound healing effect, but only a limited leishmanicidal activity notably against intracellular parasites [12] (US and CB, unpublished data), future clinical trials should investigate the combination of DAC N-055 MWT with a strong leishmanicidal regimen.

\section{Conclusions}

In CL endemic regions with poor infrastructure, bipolar HF-EC is a robust technology to debride CL lesions under local anaesthesia. The combination with DAC N-055 MWT provides additional anti-parasitic, antimicrobial and wound healing effects. Well designed and controlled prospective cohort studies with a large sample of patients and a post-treatment monitoring period of one to two years are the only way of investigating the frequency and impact of NDEs such as keloïd or hypertrophic scars, permanent pigmental disorders, or persisting erythemas. The costeffectiveness of the proposed interventions is currently under investigation.

\section{Additional files}

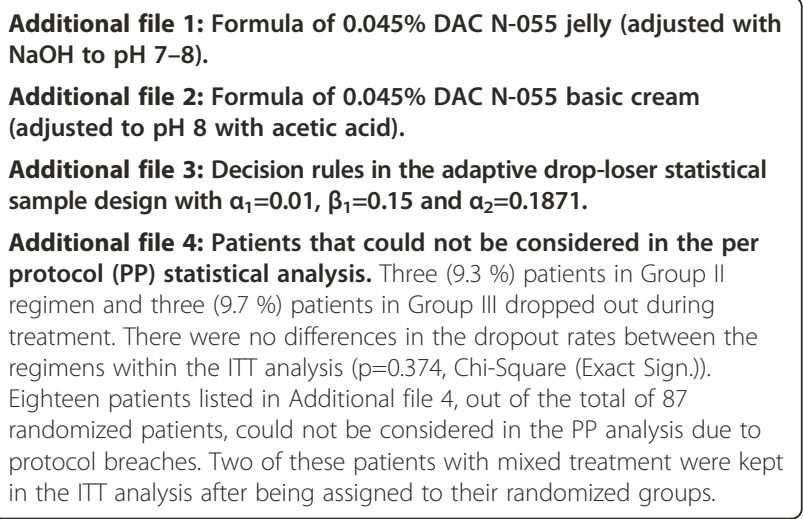

\section{Abbreviations}

AA: German Federal Foreign Office; AFPAK: Afghanistan and Pakistan Stabilization Pact; BMBF: German Federal Ministry for Education and Research; BMZ: German Federal Ministry for Economic Cooperation and Development; CAP: Cold atmospheric plasma; CL: Cutaneous leishmaniasis; DAAD: German Academic Exchange Service; DAC: German Drug Codex; DAC N-055: Pharmaceutical sodium chlorite listed in the German Drug Codex; EC 1.11.1.6: Enzyme classification; EC: Bipolar electrocauterization; GMS: German Medical Service; HF: High-frequency; ITT: Intention to treat; IZKF: Interdisciplinary Centre of Clinical Research; L. major: Leishmania major; L. tropica: Leishmania tropica; LMC: Leishmania and Malaria Centre; MoPH: Ministry of Public Health; MWT: Moist wound treatment; NDE: Non desired effects; NMLCP: National Malaria and Leishmania Control Program; NTP: Non thermal plasma; PP: Per protocol; RCT: Randomized controlled trial; ROS: Reactive oxygen species; SSG: Sodium stibogluconate; WHO: World Health Organization.

\section{Competing interests}

The funders had no role in study design, data collection, data analysis, and interpretation, decision to publish, or preparation of the manuscript. KWS and HCS are members of the Board and CB is a member of the non-profit NGO Waisenmedizin - PACEM e.V. promoting access to essential medicine.

\section{Authors' contributions}

The authors accept full responsibility for the overall content of this report. HCS, KWS, CB, and JLB designed the trial. KWS and IS were the principal investigators for the clinical part of the trial, whereas the CB and US were principal investigators for the laboratory part of the trial; FA, MLA, and IS enrolled and managed patients, collected laboratory and clinical data; HCS, KWS, US, and CB contributed to writing of the paper. HCS and JLB analysed the data. RS participated in supervision. All authors read and approved the final manuscript.

\section{Acknowledgements}

We are grateful to the National Malaria and Leishmania Control Program (NMLCP) Director at the Ministry of Public Health $(\mathrm{MoPH})$ in Kabul, Afghanistan, Sami Nahzat, MD, MPH for his administrative support; to Yousofy Ghafar, MD (Director of Leishmania and Malaria Centre (LMC), Provincial Civil Balkh Hospital, Mazar-e-Sharif, Afghanistan) for his help and local support in conducting the study; to Heidi Sebald and Andrea Debus (Mikrobiologisches Institut, Universitätsklinikum Erlangen, Germany) for their expert technical assistance and organizational help throughout the years; and to Philippe Roos (Albert-Ludwigs-Universität Freiburg, Germany) for his 
help as medical trainee during an elective period in Mazar-e-Sharif. We wish to express our sincere thanks to the German Federal Foreign Office (AA Berlin, Germany) for providing 8,000 vials of sodium stibogluconate and the funds for renovation of the LMC in Mazar-e-Sharif within the AFPAK-Stability Pact, to the German Federal Ministry for Economic Cooperation and Development (BMZ, Berlin, Germany) for installing the solar power system at the LMC in Mazar-e-Sharif, and to the German Defence Ministry for enabling the transportation of the punch biopsies from Mazar-e-Sharif to the lab of US and CB in Erlangen. We specifically thank KLS Martin GmbH (D-79224 Umkirch, Germany) for helping us to adapt the HF minicutter to biploar HF-EC. The German Academic Exchange Service (DAAD, Bonn, Germany) supported KWS with grants. US and CB were supported by the Interdisciplinary Centre of Clinical Research (IZKF, project A49), CB also by a grant within the "Medicinal Redox Inorganic Chemistry Consortium" funded by the Emerging Field Initiative (EFI) of the FAU Erlangen-Nürnberg. This study was only made possible through the initial and generous support by German Federal Ministry for Education and Research (BMBF grant AFG 08/002, RS and HCS) to the Institute of Public Health at the University Hospital Heidelberg, Germany.

\section{Funding}

German Federal Ministry for Education and Research, German Federal Foreign Office, German Federal Ministry for Economic Cooperation and Development, German Federal Defence Ministry, German Academic Exchange Service, Interdisciplinary Centre for Clinical Research of the University Hospital Erlangen, Germany, Medicinal Redox Inorganic Chemistry Consortium of the Emerging Field Initiative of the FAU Erlangen-Nürnberg.

\section{Summary of article's main point}

Cutaneous leishmaniasis results from an infection with Leishmania parasites and frequently causes chronic wounds. This study reports on a randomized controlled three-armed trial, which demonstrates the superiority in closing the skin defects of two wound-healing regimens compared to the standard chemotherapy with topical pentavalent antimony.

\section{Author details}

'Institute of Public Health, University Hospital Heidelberg, Heidelberg, Germany. ${ }^{2}$ Provincial Balkh Hospital, Mazar-e-Sharif, Afghanistan. ${ }^{3}$ Mikrobiologisches Institut - Klinische Mikrobiologie, Immunologie und Hygiene, Friedrich-Alexander-Universität (FAU) Erlangen-Nürnberg und Universitätsklinikum Erlangen, Erlangen, Germany. ${ }^{4}$ Institut für Medizinische Biometrie, Universität Heidelberg, Heidelberg, Germany. ${ }^{5}$ Waisenmedizin e.V. - PACEM, Freiburg, Germany.

Received: 2 April 2014 Accepted: 7 November 2014

Published online: 25 November 2014

\section{References}

1. Alvar J, Vélez ID, Bern C, Herrero M, Desjeux P, Cano J, Jannin J, den Boer M, WHO Leihsmaniasis Control Team: Leishmaniasis worldwide and global estimates of its incidence. PLoS One 2012, 7(5):e35671.

2. Sen CK, Gordillo GM, Roy S, Kirsner R, Lambert L, Hunt TK, Gottrup F, Gurtner GC, Longaker MT: Human skin wounds: a major and snowballing threat to public health and the economy. Wound Repair Regen 2009, 17(6):763-771. doi:10.1111/j.1524-475X.2009.00543.X.

3. Hinz J, Hautzinger H, Stahl KW: Rationale for and results from a randomised, double-blind trial of tetrachlorodecaoxygen anion complex in wound healing. Lancet 1986, 1(8485):825-828.

4. Oxoferin zur Beschleunigung der Wundheilung: BGA-Zulassung für Umstrittenen Wirkstoff. a-t. 1990, Nr. 6: 52 [http://www.arznei-telegramm. de/html/1990_06/9006052_01.html, March 19th 2014]

5. Kempf SR, Blaszkiewitz K, Reim M, Ivankovic S: Comparative study on the effects of chlorite oxygen reaction product TCDO (tetrachlorodecaoxygen) and sodium chlorite solution ( $\mathrm{NaClO} 2)$ with equimolar chlorite content on bone marrow and peripheral blood of BDIX rats. Drugs Exp Clin Res 1993, 19(4):165-174.

6. Kempf SR, Port RE, Ivankovic S: Anticarcinogenic effect of tetrachlorodecaoxide after total-body gamma irradiation in rats. Radiat Res 1994, 139(2):226-231.

7. Mayfield JA, Blanc B, Rodgers KR, Lukat-Rodgers GS, Dubois JL: Peroxidase-type reactions suggest a heterolytic/nucleophilic $\mathrm{O}-\mathrm{O}$ joining mechanism in the heme-dependent chlorite dismutase. Biochemistry 2013, 52(40):6982-6994. doi:10.1021/bi4005599. Epub 2013 Sep 23.

8. Mayfield JA, Dehner CA, DuBois JL: Recent advances in bacterial heme protein biochemistry. Curr Opin Chem Biol 2011, 15(2):260-266. doi:10.1016/j.cbpa.2011.02.002. Epub 2011 Feb 19.

9. Keith JM, Abu-Omar MM, Hall MB: Computational investigation of the concerted dismutation of chlorite ion by water-soluble iron porphyrins. Inorg Chem 2011, 50(17):7928-7930. doi:10.1021/ic2009732. Epub 2011 Aug 1.

10. Kalghatgi S, Kelly CM, Cerchar E, Torabi B, Alekseev O, Fridman A, Friedman $G$, Azizkhan-Clifford J: Effects of non-thermal plasma on mammalian cells. PLoS One 2011, 6(1):e16270. doi:10.1371/journal.pone.0016270.

11. Yu Y, Tan M, Chen H, Wu Z, Xu L, Li J, Cao J, Yang Y, Xiao X, Lian X, Lu X, Tu Y: Non-thermal plasma suppresses bacterial colonization on skin wound and promotes wound healing in mice. J Huazhong Univ Sci Technolog Med Sci 2011, 31(3):390-394. doi:10.1007/s11596-011-0387-2. Epub 2011 Jun 14.

12. Jebran AF, Schleicher U, Steiner R, Wentker P, Mahfuz F, Stahl HC, Amin FM, Bogdan C, Stahl KW: Rapid healing of cutaneous leishmaniasis by highfrequency electrocauterization and hydrogel wound care with or without DAC N-055: a randomized controlled phase lla trial in Kabul. PLoS Negl Trop Dis 2014, 8(2):e2694. doi:10.1371/journal.pntd.0002694.

13. Reithinger R, Mohsen M, Wahid M, Bismullah M, Quinnell RJ, Davies CR, Kolaczinski J, David JR: Efficacy of thermotherapy to treat cutaneous leishmaniasis caused by Leishmania tropica in Kabul, Afghanistan: a randomized, controlled trial. Clin Infect Dis 2005, 40(8):1148-1155. Epub 2005 Mar 16.

14. Morizot G, Kendjo E, Mouri O, Thellier M, Pérignon A, Foulet F, Cordoliani F, Bourrat E, Laffitte E, Alcaraz I, Bodak N, Ravel C, Vray M, Grogl M, Mazier D, Caumes E, Lachaud L, Buffet PA, Cutaneous Leishmaniasis French Study Group: Travelers with cutaneous leishmaniasis cured without systemic therapy. Clin Infect Dis 2013, 57(3):370-380. doi:10.1093/cid/cit269. Epub 2013 Apr 30.

15. Doudi M, Setorki M, Narimani M: Bacterial superinfection in zoonotic cutaneous leishmaniasis. Med Sci Monit 2012, 18(9):BR356-BR361.

16. Percival SL, Hill KE, Williams DW, Hooper SJ, Thomas DW, Costerton JW: A review of the scientific evidence for biofilms in wounds. Wound Repair Regen 2012, 20(5):647-657.

17. Modabber F, Buffet PA, Torreele E, Milon G, Croft SL: Consultative meeting to develop a strategy for treatment of cutaneous leishmaniasis. Institute Pasteur, Paris. 13-15 June, 2006. Kinetoplastid Biol Dis 2007, 6:3.

18. Stahl KW, Sakhayeee IG: Lupoid cutaneous leishmaniasis in Afghanistan treated with 0.045\% DAC N-055. BMC Proceedings 2011, 5(Suppl 6):P247.

19. Panuncialman J, Hammerman S, Carson P, Falanga V: Wound edge biopsy sites in chronic wounds heal rapidly and do not result in delayed overall healing of the wounds. Wound Repair Regen 2010, 18(1):21-25. doi:10.1111/ j.1524-475X.2009.00559.x.

20. Faulde MK, Heyl G, Amirih ML: Zoonotic cutaneous leishmaniasis. Afghanistan. Emerg Infect Dis 2006, 12(10):1623-1624.

21. German Priorities 19907256.6 (19th February 1999) and 19950632.9 (20th October 1999): Peroxochloric acid, derivatives, and anions, salts thereof, method for producing them and use of the same. http://patentscope.wipo.int/ search/en/detail.jsf?docld=WO2000048940\&recNum=1\&office=\&queryString=FP\% 3A\%28WO2000048940\%29\&prevFilter=\&sortOption=Pub+Date+Desc\&maxRec $=1$.

22. Migdal C, Serres M: Reactive oxygen species and oxidative stress. Med Sci (Paris) 2011, 27(4):405-412. doi:10.1051/medsci/2011274017. Epub 2011 Apr 28.

23. Stone JR, Yang S: Hydrogen peroxide: a signaling messenger. Antioxid Redox Signal 2006, 8(3-4):243-270.

24. Elstner EF: Heme activated oxidations using the chlorite-oxygen complex "TCDO" (Oxoferin)-an overview. Z Naturforsch C 1988, 43(11-12):893-902.

25. Zeglin O: Infektiologie und Tropendermatologie - Teil 17: Kutane Leishmaniasis - eine Kasuistik mit Nachbegutachtung. Derm 2009, 15(4):246ff.

26. Al-Hucheimi SN, Sultan BA, Al-Dhalimi MA: A comparative study of the diagnosis of Old World cutaneous leishmaniasis in Iraq by polymerase chain reaction and microbiologic and histopathologic methods. Int J Dermatol 2009, 48(4):404-408. doi:10.1111/j.1365-4632.2009.03903.x.

27. Hochberg Y, Tamhane AC: Multiple Comparison Procedures. New York, NY, USA: John Wiley \& Sons, Inc; 1987.

28. Gottrup F, Apelqvist J, Price P, European Wound Management Association Patient Outcome G: Outcomes in controlled and comparative studies on non-healing wounds: recommendations to improve the quality of evidence in wound management. J Wound Care 2010, 19(6):237-268. 
29. Keast DH, Bowering CK, Evans AW, Mackean GL, Burrows C, D'Souza L: MEASURE: A proposed assessment framework for developing best practice recommendations for wound assessment. Wound Repair Regen 2004, 12(3 Suppl):S1-S17.

30. Olliaro P, Vaillant M, Arana B, Grogl M, Modabber F, Magill A, Lapujade O, Buffet P, Alvar J: Methodology of clinical trials aimed at assessing interventions for cutaneous leishmaniasis. PLOS Negl Trop Dis 2013, 7(3):e2130. doi:10.1371/journal.pntd.0002130. Epub 2013 Mar 21.

31. Aronson NE, Wortmann GW, Byrne WR, Howard RS, Bernstein WB, Marovich MA, Polhemus ME, Yoon IK, Hummer KA, Gasser RA Jr, Oster CN, Benson PM: A randomized controlled trial of local heat therapy versus intravenous sodium stibogluconate for the treatment of cutaneous Leishmania major infection. PLoS Negl Trop Dis 2010, 4(3):e628. doi:10.1371/journal.pntd.0000628.

32. Safi N, Davis GD, Nadir M, Hamid H, Robert LL, Case AJ: Evaluation of thermotherapy for the treatment of cutaneous leishmaniasis in Kabul, Afghanistan: a randomized controlled trial. Mil Med 2012, 177(3):345-351.

33. Evangelou G, Krasagakis K, Giannikaki E, Kruger-Krasagakis S, Tosca A: Successful treatment of cutaneous leishmaniasis with intralesional aminolevulinic acid photodynamic therapy. Photodermatolo Photoimmunol Photomed 2011, 27(5):254-256. doi:10.1111/j.1600-0781.2011.00610.x.

34. Ghaffarifar F, Jorjani O, Mirshams M, Miranbaygi MH, Hosseini ZK: Photodynamic therapy as a new treatment of cutaneous leishmaniasis. East Mediterr Health J 2006, 12(6):902-908.

35. Asilian A, Davami M: Comparison between the efficacy of photodynamic therapy and topical paromomycin in the treatment of Old World cutaneous leishmaniasis: a placebo-controlled, randomized clinical trial. Clin Exp Dermatol 2006, 31(5):634-637. Epub 2006 Jun 15.

36. Morton CA, Szeimies RM, Sidoroff A, Braathen LR: European guidelines for topical photodynamic therapy part 2: emerging indications-field cancerization, photorejuvenation and inflammatory/infective dermatoses. J Eur Acad Dermatol Venereol 2013, 27(6):672-679. doi:10.1111/ jdv.12026. Epub 2012 Nov 26.

37. Asilian A, Sadeghinia A, Faghihi G, Momeni A: Comparative study of the efficacy of combined cryotherapy and intralesional meglumine antimoniate (Glucantime) vs. cryotherapy and intralesional meglumine antimoniate (Glucantime) alone for the treatment of cutaneous leishmaniasis. Int J Dermato/ 2004, 43(4):281-283.

38. Asilian A, Sadeghinia A, Faghihi G, Momeni A, Amini Harandi A: The efficacy of treatment with intralesional meglumine antimoniate alone, compared with that of cryotherapy combined with the meglumine antimoniate or intralesional sodium stibogluconate, in the treatment of cutaneous leishmaniasis. Ann Trop Med Parasitol 2003, 97(5):493-498.

39. Layegh P, Pezeshkpoor F, Soruri AH, Naviafar P, Moghiman T: Efficacy of cryotherapy versus intralesional meglumine antimoniate (glucantime) for treatment of cutaneous leishmaniasis in children. Am J Trop Med Hyg 2009, 80(2):172-175.

40. Shamsi Meymandi S, Zandi S, Aghaie H, Heshmatkhah A: Efficacy of CO(2) laser for treatment of anthroponotic cutaneous leishmaniasis, compared with combination of cryotherapy and intralesional meglumine antimoniate. J Eur Acad Dermatol Venereol 2011, 25(5):587-591. doi:10.1111/ j.1468-3083.2010.03781.x.

41. Asilian A, Sharif A, Faghihi G, Enshaeieh S, Shariati F, Siadat AH: Evaluation of $\mathrm{CO}_{2}$ laser efficacy in the treatment of cutaneous leishmaniasis. Int J Dermatol 2004, 43(10):736-738.

42. Babajev KB, Babajev OG, Korepanov VI: Treatment of cutaneous leishmaniasis using a carbon dioxide laser. Bull World Health Organ 1991, 69(1):103-106.

43. Rodríguez ME, Inguanzo P, Ramos A, Pérez J: Treatment of cutaneous leishmaniasis with CO2 laser radiation. Rev Cubana Med Trop 1990, 42(2):197-202.

44. Bryan N, Ahswin H, Smart N, Bayon Y, Wohlert S, Hunt JA: Reactive oxygen species (ROS)-a family of fate deciding molecules pivotal in constructive inflammation and wound healing. Eur Cell Mat 2012, 24:249-265.

45. Isbary G, Morfill G, Schmidt HU, Georgi M, Ramrath K, Heinlin J, Karrer S, Landthaler M, Shimizu T, Steffes B, Bunk W, Monetti R, Zimmermann JL, Pompl R, Stolz W: A first prospective randomized controlled trial to decrease bacterial load using cold atmospheric argon plasma on chronic wounds in patients. Br J Dermatol 2010, 163(1):78-82. doi:10.1111/j.13652133.2010.09744.x. Epub 2010 Mar 5.
46. Isbary G, Heinlin J, Shimizu T, Zimmermann JL, Morfill G, Schmidt HU, Monetti R, Steffes B, Bunk W, Li Y, Klaempfl T, Karrer S, Landthaler M, Stolz $W$ : Successful and safe use of 2 min cold atmospheric argon plasma in chronic wounds: results of a randomized controlled trial. Br J Dermatol 2012, 167(2):404-410. doi:10.111/j.1365-2133.2012.10923.x. Epub 2012 Jul 10.

47. González U, Pinart M, Reveiz L, Alvar J: Interventions for Old World cutaneous leishmaniasis. Cochrane Database Syst Rev 2008, 4:CD005067. doi:10.1002/14651858.CD005067.pub3.

48. Giorgio M, Trinei M, Migliaccio E, Pelicci PG: Hydrogen peroxide: a metabolic by-product or a common mediator of ageing signals? Nat Rev Mol Cell Biol 2007, 8(9):722-728.

49. Scales BS, Huffnagle GB: The microbiome in wound repair and tissue fibrosis. J Pathol 2013, 229(2):323-331. doi:10.1002/path.4118. Epub 2012 Nov 29.

50. Wang $X$, Fang H, Huang Z, Shang W, Hou T, Cheng A, Cheng H: Imaging ROS signaling in cells and animals. J Mol Med (Berl) 2013, 91(8):917-927. doi:10.1007/s00109-013-1067-4. Epub 2013 Jul 20.

51. Arndt S, Unger P, Wacker E, Shimizu T, Heinlin J, Li YF, Thomas HM, Morfill GE, Zimmermann JL, Bosserhoff AK, Karrer S: Cold atmospheric plasma (CAP) changes gene expression of Key molecules of the wound healing machinery and improves wound healing in vitro and in vivo. PLOS One 2013, 8(11):e79325. doi:10.1371/journal.pone.0079325.

52. Hinz J, Kuhne FW, Stahl KW: Local tetrachlorodecaoxide to improve oxygen supply to Hon-healing wounds. Lancet 1984, 2(8403):630.

53. Kazemi-Rad E, Mohebali M, Khadem-Erfan MB, Saffari M, Raoofian R, Hajjaran H, Hadighi R, Khamesipour A, Rezaie S, Abedkhojasteh H, Heidari M: Identification of antimony resistance markers in Leishmania tropica field isolates through a cDNA-AFLP approach. Exp Parasito/ 2013, 135(2):344-349. doi:10.1016/j.exppara.2013.07.018. Epub 2013 Aug 6.

54. Ryan RW, Wolf T, Spetzler RF, Coons SW, Fink Y, Preul MC: Application of a flexible $\mathrm{CO}(2)$ laser fiber for neurosurgery: laser-tissue interactions. J Neurosurg 2010, 112(2):434-443. doi:10.3171/2009.7.JNS09356.

55. Sakthianandeswaren A, Elso CM, Simpson K, Curtis JM, Kumar B, Speed TP, Handman E, Foote SJ: The wound repair response controls outcome to cutaneous leishmaniasis. Proc Natl Acad Sci U S A 2005, 102(43):15551-15556. Epub 2005 Oct 13.

56. Baldwin T, Sakthianandeswaren A, Curtis JM, Kumar B, Smyth GK, Foote SJ, Handman E: Wound healing response is a major contributor to the severity of cutaneous leishmaniasis in the ear model of infection. Parasite Immunol 2007, 29(10):501-513.

57. Elso C, Kumar B, Smyth G, Foote S, Handman E: Dissociation of disease susceptibility, inflammation and cytokine profile in Imr1/2 congenic mice infected with Leishmania major. Genes Immun 2004, 5(3):188-196. PMID: 14762398.

58. Elso CM, Roberts LJ, Smyth GK, Thomson RJ, Baldwin TM, Foote SJ, Handman E: Leishmaniasis host response loci (Imr1-3) modify disease severity through a Th1/Th2-independent pathway. Genes Immun 2004, 5(2):93-100. PMID: 14668789

59. Jakopitsch C, Pirker KF, Flemmig J, Hofbauer S, Schlorke D, Furtmüller PG, Arnhold J, Obinger C: Mechanism of reaction of chlorite with mammalian heme peroxidases. J Inorg Biochem 2014, 135:10-19. doi:10.1016/j. jinorgbio.2014.02.010. Epub 2014 Feb 28. PMID: 24632343.

\section{doi:10.1186/s12879-014-0619-8}

Cite this article as: Stahl et al:: A randomized controlled phase IIb wound healing trial of cutaneous leishmaniasis ulcers with $0.045 \%$ pharmaceutical chlorite (DAC N-055) with and without bipolar high frequency electro-cauterization versus intralesional antimony in Afghanistan. BMC Infectious Diseases 2014 14:619. 